$\begin{array}{cc}\text { Author(s): } & \begin{array}{l}\text { Harunori Takeda } \\ \text { James H. Billen } \\ \text { Subrata Nath }\end{array} \\ & \text { LANSCE-1 } \\ \text { LANSCE-1 } \\ \text { LANSCE-1 }\end{array}$

RECEIVED

AUG 141997

Submitted To: 1997 Particle Accelerator Conference

Vancouver, BC, Canada

May 12-16, 1997

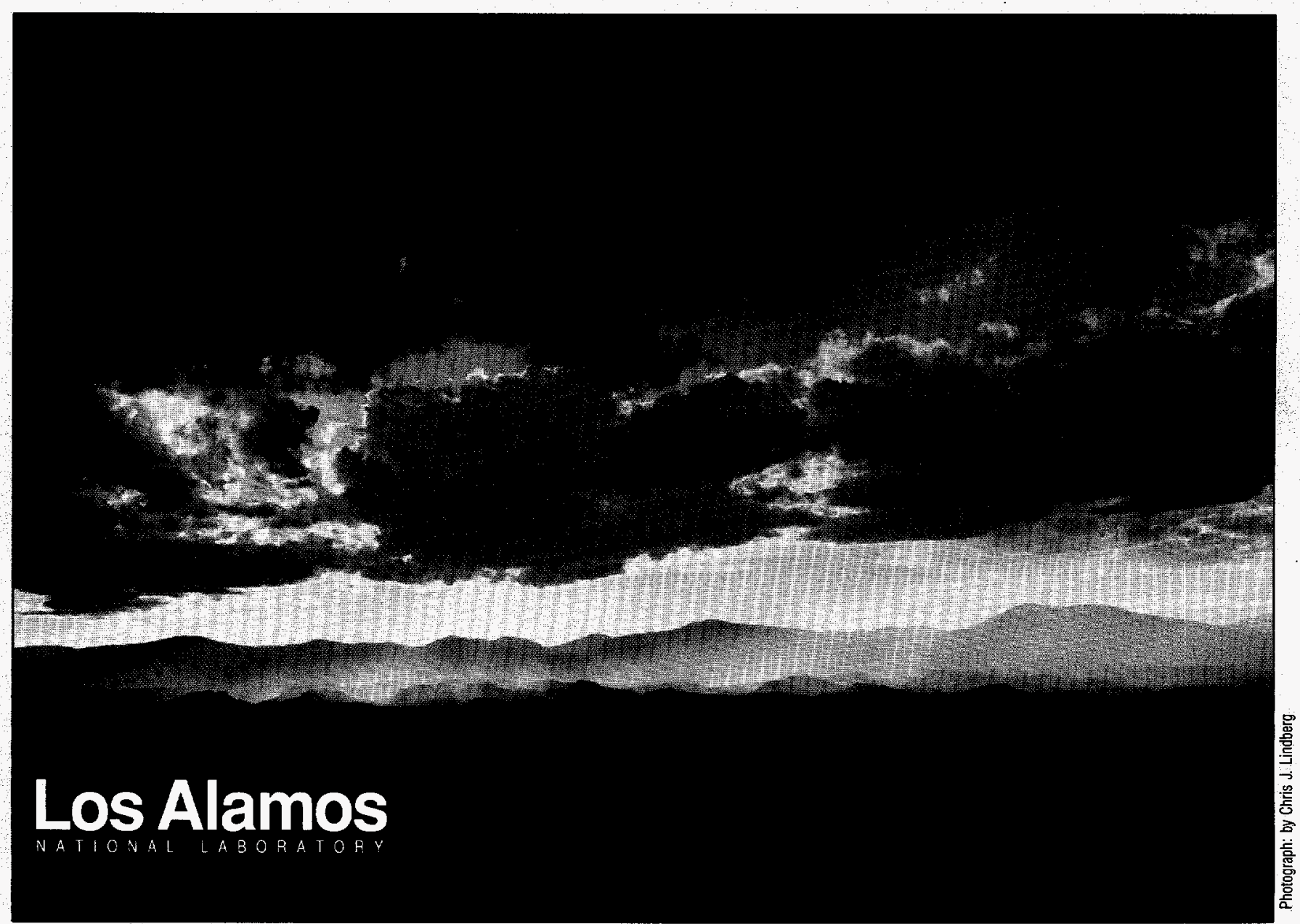

This is a preprint of a paper intended for publication in a joumal or proceedings. Because changes may be made before publication, this preprint is made available with the understanding that it will not be cited or reproctuced without the permission of the author. 


\title{
PHYSICS DESIGN OF THE NATIONAL SPALLATION NEUTRON SOURCE LINAC*
}

\author{
H. Takeda, J. H. Billen, and S. Nath \\ Los Alamos National Laboratory, Los Alamos NM 87545, USA
}

\section{Abstract}

The National Spallation Neutron Source (NSNS) requires a linac that accelerates a $\mathrm{H}^{-}$beam to $1.0 \mathrm{GeV}$. The linac starts with a radio-frequency quadrupole (RFQ) accelerator, which is followed by a drift-tube linac (DTL), a coupled-cavity drift-tube linac (CCDTL), and a conventional coupled-cavity linac (CCL). In this paper, we focus on the DTL, CCDTL, and CCL parts of the accelerator. We discuss the linac design parameters and beam dynamics issues. The design rationale of no separate matching sections between different accelerating sections maintains the current independence of beam behavior.

\section{LINAC DESIGN AND BEAM DYNAMICS}

The NSNS linac starts with a $2.5-\mathrm{MeV}$ RFQ followed by a beam transport and matching section that includes a fast chopper. We report studies of a matched beam from the exit of the beam transport section injected into the 2.5-to$20-\mathrm{MeV}$ DTL, which is followed by a CCDTL[1] and a conventional CCL. Figure 1 shows schematically the layout of the CCDTL and CCL sections of the linac. We use the term segment to refer to a contiguous section of accelerating structure plus the space between cavities for electromagnetic quadrupole lenses. After the DTL, we maintain a constant 11- $\beta \lambda$-long transverse focusing period through the rest of the linac, where $\beta \lambda$ is the distance traveled by a particle of velocity $\beta c$ in one rf period.

A future upgrade of NSNS from 1 to $4 \mathrm{MW}$ total beam power will require duplication of the components below $20 \mathrm{MeV}$ and installation of a beam funnel. The rest of the linac remains the same, except for a reconfiguration of the $\mathrm{rf}$ modules to handle the added beam power. The original installation of the CCDTL and CCL will include a sufficient number of power irises for the upgrade.

\section{Drift-Tube Linac: 2.5 to $20 \mathrm{MeV}$}

The $402.5-\mathrm{MHz}$ DTL accelerates the $2.5-\mathrm{MeV}$ beam to 20.27 MeV. Permanent-magnet quadrupole lenses inside the drift tubes, arranged in a FOFODODO lattice, provide the transverse focusing. The lattice period has length $4 \beta \lambda$ at $402.5 \mathrm{MHz}$. At the front end, each lens has $\mathrm{G} l=24 \mathrm{kG}$, which corresponds to a zero-current transverse phase advance $\sigma_{0 t}=74 \mathrm{deg} /$ period. The transverse focusing gradually weakens to $\mathrm{G} l=17.08 \mathrm{kG}, \sigma_{0 \mathrm{t}}=59 \mathrm{deg} /$ period

\footnotetext{
*This work sponsored by the Division of Materials Sciences, US Department of Energy, under contract number DE-AC05-96OR22464 with Lockheed Martin Energy Research Corporation for Oak Ridge National Laboratory.
}

at the exit. The longitudinal phase advance $\sigma_{01}$ starts at 61 $\mathrm{deg} /$ period and ends at $40 \mathrm{deg} / \mathrm{period}$. The accelerating gradient is kept constant at $\mathrm{E}_{0}=3.0 \mathrm{MV} / \mathrm{m}$.

In the CCDTL, the if structure frequency doubles. Also, the periodicity of the transverse focusing lattice changes to $11 \beta \lambda$ at $805 \mathrm{MHz}$, which is a $37.5 \%$ increase in length compared to $4 \beta \lambda$ at $402.5 \mathrm{MHz}$. We use this frequency and focusing period through the CCL.

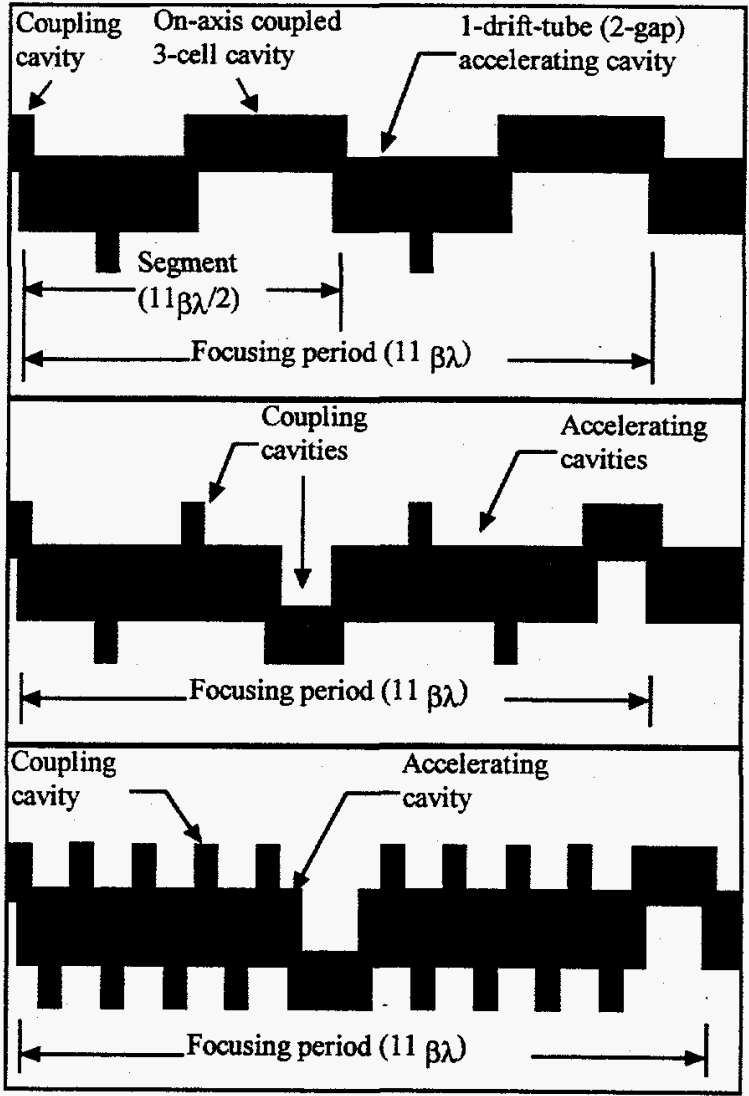

Figure 1. Layout of CCDTL and CCL sections. From 20 to $67 \mathrm{MeV}$ (top), segments contain two cavities plas a $5 \beta \lambda / 2$ space for a magnet. From 67 to $95 \mathrm{MeV}$ (middle), segments contain three cavities plus a $1 \beta \lambda$ space. Above $95 \mathrm{MeV}$ (bottom), the CCL has nine cavities and a $1 \beta \lambda$ space.

\section{Coupled-Cavity Drift-Tube Linac: 20 to $95 \mathrm{MeV}$}

The top part of Figure 1 shows two 2-gap cavities in a CCDTL segment for the energy range from 20 to 67.7 $\mathrm{MeV}$. Each cavity contains one internal drift tube mounted on stems. Electromagnetic quadrupole magnets mounted external to the rf structure provide the transverse focusing. The bore radius in this section is $1.059 \mathrm{~cm}$. At 67.7 MeV, we switch to three 2-gap cavities per segment, 


\section{DISCLAMIER}

Portions of this document may be illegible in electronic image products. Images are produced from the best available original document. 


\section{DISCLAIMER}

This report was prepared as an account of work sponsored by an agency of the United States Government. Neither the United States Government nor any agency thereof, nor any of their employees, make any warranty, express or implied, or assumes any legal liability or responsibility for the accuracy, completeness, or usefulness of any information, apparatus, product, or process disclosed, or represents that its use would not infringe privately owned rights. Reference herein to any specific commercial product, process, or service by trade name, trademark, manufacturer, or otherwise does not necessarily constitute or imply its endorsement, recommendation, or favoring by the United States Government or any agency thereof. The views and opinions of authors expressed herein do not necessarily state or reflect those of the United States Government or any agency thereof. 
as shown in the middle part of Figure 1. At this point, the bore radius increases to $1.505 \mathrm{~cm}$. In a symmetric design all the cavities of a segment are identical: their length corresponds to the average velocity of the particles in the segment. Successive segments lengthen as $\beta$ increases.

The choices for frequency and focusing lattice impose conditions on matching between structures. We require that $\sigma_{0 t}$ and $\sigma_{01}$ be continuous across the transition between the DTL and CCDTL. For both $x$ and $y$ transverse planes, $\sigma_{0 t}=59.0 \mathrm{deg} /$ period and $\sigma_{01}=39.6$ $\mathrm{deg} /$ period for a period of $4 \beta \lambda$ in the $402.5 \mathrm{-MHz}$ DTL. In the CCDTL, we need $\sigma_{0 t}=80.0 \mathrm{deg} /$ period and $\sigma_{01}=$ $55.0 \mathrm{deg} /$ period for a period of $11 \beta \lambda$ at $805 \mathrm{MHz}$. At 20 $\mathrm{MeV}$, the required strength of the quadrupole magnets in the CCDTL FODO lattice is $\mathrm{Gl}=22.77 \mathrm{kG}$, and the required accelerating gradient is $E_{0}=2.40 \mathrm{MV} / \mathrm{m}$. We match the DTL output beam into the CCDTL by adjusting the first four quadrupole gradients and the first two CCDTL cavity gradients. The phases of these cavities are set to -90 degrees to act as bunchers. When the funnel is eventually installed, it will provide a beam that matches the beam characteristics at the output of the DTL.

The design $\mathrm{rf}$ phase through the CCDTL ramps smoothly from -40 degrees at $20 \mathrm{MeV}$ to -30 degrees at $95 \mathrm{MeV}$. The accelerating gradient is discontinuous across changes in the rf structure so that the average of $E_{0} T$ over a focusing period is continuous, where $T$ is the transit-time factor. Figure 2 shows $E_{0}$ as a function of beam energy along the accelerator.

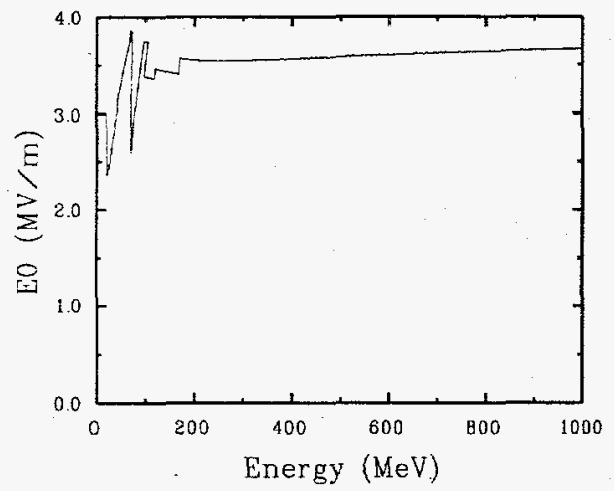

Figure 2. Accelerating gradient versus energy. The discontinuities between structures make accelerating field per unit length vary smoothly.

\section{Coupled-Cavity Linac: $95 \mathrm{MeV}$ to $1 \mathrm{GeV}$}

A CCL segment consists of 9 identical cavities as shown in the bottom of Figure 1. Drift spaces for quadrupole magnets have length $\beta \lambda$. For a nearly constant accelerating gradient $E_{0} \sim 3.36$ to $3.67 \mathrm{MV} / \mathrm{m}$, the longitudinal focusing drops substantially thorough the CCL: $\sigma_{01}=75.0 \mathrm{deg} / \mathrm{period}$ at entry and $\sigma_{01}=17.0$ $\mathrm{deg} /$ period at $1 \mathrm{GeV}$. To reduce the energy transfer from the transverse to the longitudinal phase plane, we reduce the quadrupole strength $\mathrm{G} l$ from 22.65 to $10.5 \mathrm{kG}$.

The computer code PARMILA[2] designs the cavity for each segment and simulates the beam-dynamics performance through all sections of the linac. We inject a beam of 10,000 macroparticles into the DTL with 27.5-
$\mathrm{mA}$ peak current. Figure 3 shows the $\mathrm{x}$ position, phase, and energy profiles through the CCL to the final energy of $1 \mathrm{GeV}$. Figure 4 shows the beam phase space distributions $x-x^{\prime}, y-y^{\prime}$, and $\Delta \phi-\Delta W$ at the center of the last quadrupole magnet. The figure also includes a plot of the $x-y$ spatial distribution.

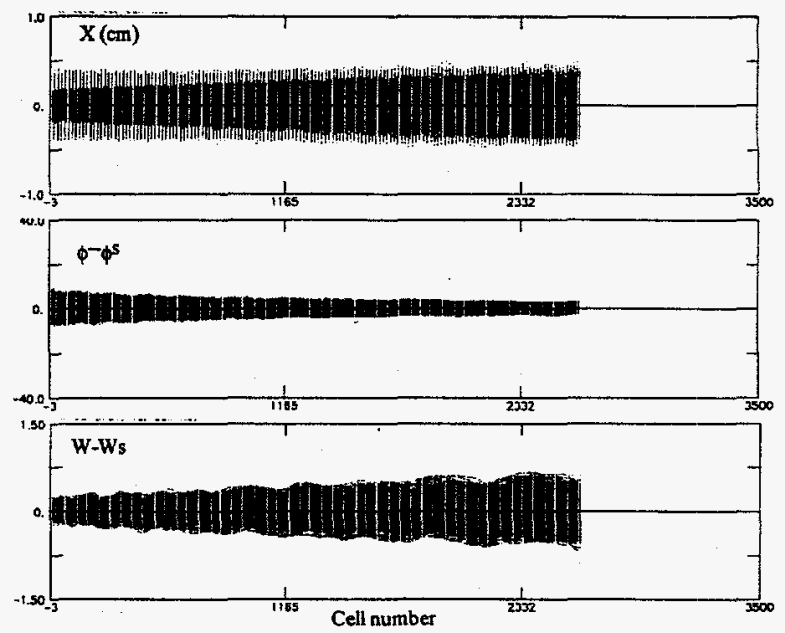

Figure 3. Beam profiles along the CCL versus cell number. The top panel shows the $x$ position, the middle shows phase, and the bottom shows energy.
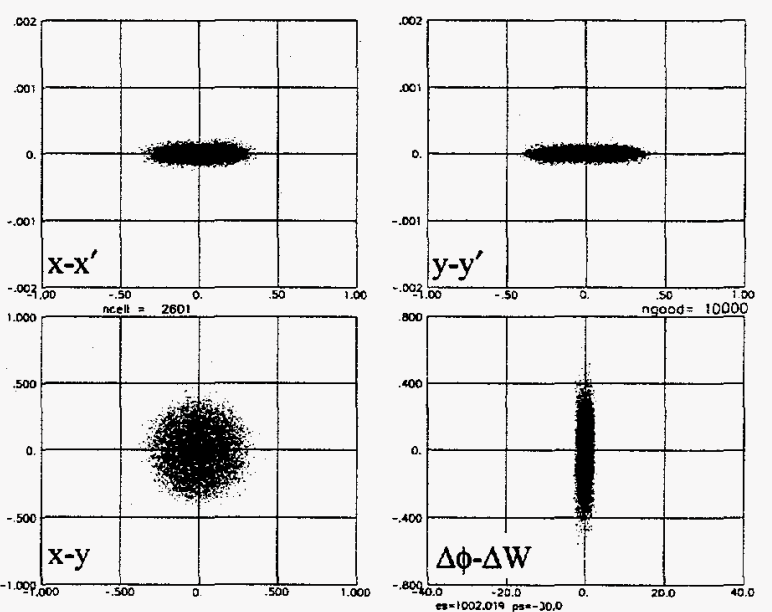

Figure 4. The beam phase space distributions at the center of last quadrupole lens in the CCL.

\section{DESIGN PARAMETERS}

In designing the $\mathrm{rf}$ cavities, the bore radius in the CCDTL and CCL strongly affects the cavity efficiency as measured by the shunt impedance. Figure 5 shows the effective shunt impedance per unit length $\mathrm{ZT}^{2}$ calculated by the SUPERFISH [3] program for several series of cavities optimized for good shunt impedance. The data presented here include the effects of power losses on stems in the CCDTL as well as an estimate of the additional power losses near coupling slots in both the CCDTL and CCL. We chose cavities with $\mathrm{ZT}^{2}$ larger than about $35 \mathrm{M} \Omega / \mathrm{m}$. The CCDTL has three different bore radii starting at $1.059 \mathrm{~cm}$ and the $C C L$ has four bore radii increasing up to $2.216 \mathrm{~cm}$. 
Table 1 lists a few of the design parameters for the three sections of the NSNS linac. Most parameters have been defined elsewhere in this paper. The synchronous phase of the design particles is $\phi_{s}$, the initial and final energies of a section are $W_{i}$ and $W_{f}$, and $L$ is the length.

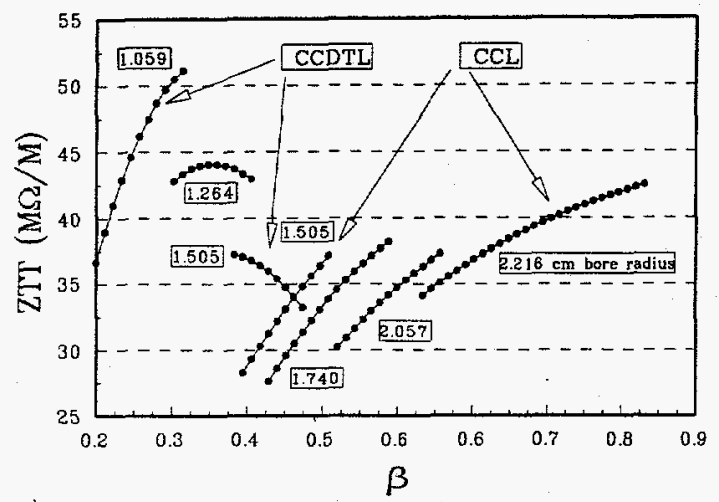

Figure 5. Shunt impedance computed by SUPERFISH depends on the beam velocity $\beta$ and the cavity bore radius.

Table 1. Linac Parameters.

\begin{tabular}{|l|c|c|c|}
\hline Structure & DTL & CCDTL & CCL \\
\hline Lattice & FOFODODO & FODO & FODO \\
\hline $\mathrm{f}(\mathrm{MHz})$ & 402.5 & 805.0 & 805.0 \\
\hline $\mathrm{E}_{0}(\mathrm{MV} / \mathrm{m})$ & 3.0 & 2.36 to 3.70 & 3.38 to 3.67 \\
\hline $\mathrm{G} l(\mathrm{kG})$ & 24.0 to 17.1 & 22.8 & 22.7 to 10.5 \\
\hline$\phi_{\mathrm{s}}($ degrees $)$ & -30 & -40 to -30 & -30 \\
\hline $\mathrm{W}_{\mathrm{i}}(\mathrm{MeV})$ & 2.5 & 20.27 & 95.39 \\
\hline $\mathrm{W}_{\mathrm{f}}(\mathrm{MeV})$ & 20.27 & 95.39 & 1000.0 \\
\hline $\mathrm{L}(\mathrm{m})$ & 8.71 & 59.34 & 424.4 \\
\hline
\end{tabular}

\section{BEAM CHARACTERISTICS}

The beam emittances were calculated by the simulation code PARMILA starting from the DTL entrance at 2.5 $\mathrm{MeV}$ to the $\mathrm{CCL}$ exit at $1 \mathrm{GeV}$. We started with an emittance of $0.0175 \pi \mathrm{cm}$-mrad for both transverse phase planes and $0.08865 \pi \mathrm{MeV}$-deg for the longitudinal phase space. The $\mathrm{G} l$ product of the quadrupole magnets changes through the CCL to gradually reduce the beam partitioning ratio $[4,5]$ from 1.8 at $100 \mathrm{MeV}$ to 1.4 at 1 $\mathrm{GeV}$. A partitioning ratio of 1.0 corresponds to an equipartitioned beam. A value larger than unity indicates an excess of transverse focusing. Figure 6 shows the transverse ( $x$ and $y$ ) normalized rms emittance and the longitudinal normalized emittance along the linac. An unavoidable mismatch between the DTL and CCDTL causes some emittance growth and an increase in beam size early in the CCDTL, but the emittance and size remains nearly constant through the rest of the linac.

The rms beam radius and the maximum size in the $x$ coordinate are plotted in Figure 7. The figure also shows the drift-tube inner radii along the linac. The maximum beam radius of $5 \mathrm{~mm}$ compared to a large beam tube reduces the beam loss in the linac. The consequences of beam loss are more serious at high energy than at low energy. The smaller bore radii below $200 \mathrm{MeV}$ improve the shunt impedance.

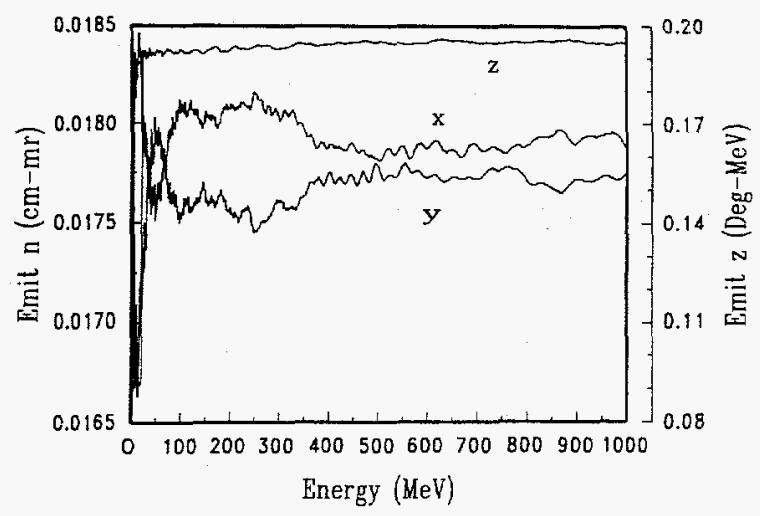

Figure 6. Transverse ( $x$ and $y$ ) and longitudinal (z) normalized emittances versus beam energy.

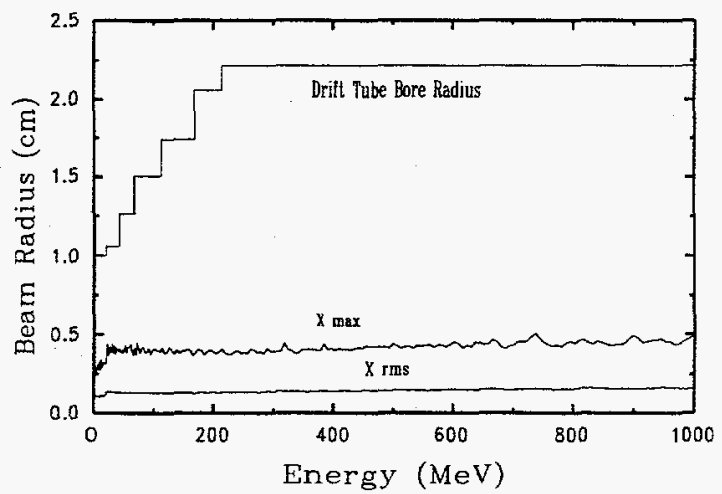

Figure 7. The beam's maximum radius and the rms radius along the linac compared to the beam aperture.

\section{CONCLUSION}

The current design of the NSNS linac shows that we can accelerate beam from the DTL through the CCL to $1 \mathrm{GeV}$ without appreciable emittance growth or beam-size growth. The beam is well contained within the aperture. The match between the DTL and the CCDTL might be further refined to reduce the emittance growth at that junction. Also, the funnel section that combines two DTL beams into the CCDTL requires further work.

\section{REFERENCES}

[1] J. H. Billen, F. L. Krawczyk, R. L. Wood, and L. M. Young, "A New RF Structure for Intermediate-Velocity Particles," Proceedings of the 1994 International Linac Conference, Vol. 1, p. 341 (August 21-26, 1994).

[2] H. Takeda and J. E. Stovall, "Modified PARMILA Code for New Accelerating Structures," Proceedings of the 1995 Particle Accelerator Conference, p. 2364 (May 1-5, 1995, Dallas, Texas).

[3] J. H. Billen and L. M. Young, "POISSON SUPERFISH," LoS Alamos National Laboratory report LA-UR-96-1834 (revision April 22, 1997).

[4] L. M. Young, "Equipartitioning In A High Current Proton Linac," this conference.

[5] Martin Reiser, "Theory and Design of Charged Particle Beams," John Wiley \& Sons, Inc., p. 573 (1994) 